\title{
Applications of Glass and Glass Fiber Retrofit Polymer in Modern Footbridges
}

\author{
Beata Stankiewicz and Marcin Tatara \\ Faculty of Civil Engineering, Opole University of Technology Poland, Damroki 80-177, Poland
}

\begin{abstract}
The architecture of footbridge design takes the form of a number of submissions from leading architects and engineers, each setting out their views on bridge design — present and future. It looks at the functions of a bridge, defining purpose of place and context, the spirit of creativity and the reasoned progression of an idea. It also explores the exploitation of materials technology and construction innovation and the tension between lightness and mass and between sculpture and scale. Present parameters of tempered and laminated glass create possibility of modern architecture of footbridges which are being full of transparency and light reflex effects. Four projects, using glass panels designed by Santiago Calatrava, have been presented in this paper. GFRP (glass fiber retrofit polymer) makes new horizon in material technology, helps to enrich new conception of structure with longer durability, low weight of deck and new creation of architecture line. The paper has described a few results of FEM (finite element method) analysis of footbridge with modular bridge GFRP deck system. The footbridge was excited by impact and human-induced vibrations. Composite material consists of glass fibers and polymer matrix is a promising alternative against traditional materials. New architecture and modern material engineering are looking for fresh possibilities of form and shape of structure, long durability and extraordinary technical parameters of building elements.
\end{abstract}

Key words: Transparent bridge deck, parameters of glass, GFRP deck, pultruded material, FEM of bridge deck, fiberline technology.

\section{Introduction}

Present footbridge structures in the world are like explosion of modern engineering calculation and material parameters. They are full of amazing architectures and extraordinary forms and shapes. Engineers predict that a new type of footbridge, a hybrid design in incorporating suspension and cable-stayed features will revolutionize bridge design, as will high-strength. Light composites are used and create new dimension of bridge designed.

The potential of using tempered glass and GFRP (glass fibre retrofit polymer) in footbridge structures is very huge. Development of glass material creates new horizon for interesting esthetical form of footbridges with delicate transparent effect. Many footbridges with transparent glass deck and glass balustrades have been designed by famous architects and engineers in the world [1, 11]. Glass panels create special light

Corresponding author: Beata Stankiewicz, Ph.D., research field: bridge structures. E-mail: b.stankiewicz@po.opole.pl. dimension of structure with illuminations. The main and important parameters of tempered and laminated glass have special possibilities in designing process of extraordinary footbridges. GFRP composites, thanks to their beneficial properties and various advantages over traditional materials, have great potential as a material used in bridge engineering. During the last 30 years, they have been proved useful in a few areas: they are commonly used to strengthen existing bridge structures and can replace traditional materials for structural elements in hybrid bridge structures.

\section{Glass Panels in Modern Footbridges}

\subsection{The Safety Standard of Thermally Tempered and Laminated Glass}

The parameter of tensile strength for ordinary glass is $40 \mathrm{MPa}\left(\mathrm{N} / \mathrm{mm}^{2}\right)$, but the same parameter for tempered glass is $120 \sim 200 \mathrm{MPa}\left(\mathrm{N} / \mathrm{mm}^{2}\right)$. The safety of thermally tempered glass depends on the thickness of it, the processing of edges and whether there are 
holes in the glass sheet. Thermal tempering also changes the way glass fractures - if broken, thermally tempered glass shatters into small particles not particularly hazardous to people. All float glass contains some level of imperfection. One type of imperfection is nickel sulphide $\left(\mathrm{N}_{\mathrm{i}} \mathrm{S}\right)$ inclusions. Most $\mathrm{N}_{\mathrm{i}} \mathrm{S}$ inclusions are stable and cause no problems. There is, however, a potential for $\mathrm{N}_{\mathrm{i}} \mathrm{S}$ inclusions that may cause spontaneous breakage in fully tempered glass without any load or thermal stress being applied. Heat soak testing is a process that exposes critical $\mathrm{N}_{\mathrm{i}} \mathrm{S}$ inclusions in fully tempered glass. Technical material parameters are very important for safety and structure durability but architectural shape of footbridges using glass is equally important. Transparency of deck and balustrades gives light and interesting impression to the whole structure. The development of material engineering implicates extraordinary possibilities for modern forms of building structures with high and long durability [3].

\subsection{Amazing Architecture of Footbridges Using Glass} Decks and Balustrades

\subsubsection{The Petah Tikva Footbridge}

Cable stayed footbridge, the Petah Tikva, from 2005, has got main span with $50 \mathrm{~m}$ constructed by steel and glass panels. The deck consists of two back parts with the same transparent deck with $39 \mathrm{~m}$ each other [10]. Pylon is situated outside the deck of the structure and it has special light individual form which splendidly cooperates with curve and azure deck. This footbridge is original symbol of place in modern district, $12 \mathrm{~km}$ from Tel Aviv. Glass panels have been constructed by tempered and laminated glass, integrally connected with steel profiles (Fig. 1). Petah Tikva is one of the many examples of Santiago Calatrava's projects using bridge deck covered by glass in warm climate in chosen part of the world.

\subsubsection{Original Footbridge from Jerusalem}

The Chords Bridge is another structure created by Santiago Calatrava. Footbridge is a cable stayed form with asymmetric pylon of $118 \mathrm{~m}$, with $160 \mathrm{~m}$ length curved deck using 66 steel cables in stayed system. The shape of the whole structure is like a harp, favorite instrument of legendary King David (from Jerusalem). Bridge structure is similar to sculpture in open free dimension and similar to invitation gate to historical city. Interesting form and transparency have been constructed by glass panels on deck and glass balustrades, full of reflex light effects (Fig. 2) [5, 6].

2.2.3 Transparent Footbridge across Canal Grande

Italian Venice is localized near Murano Island, very famous from factory of historical glass. The modern, new footbridge across Canal Grande, created in Santiago Calatrava's vision, is full of transparent glass but of course with perfect tensile strength and fatigue parameters, according to new standard. Architecture of Venice structure has found influence to old arch footbridges over Canal Grande [12]. The arch of the described bridge has got genius proportion 16:1. The

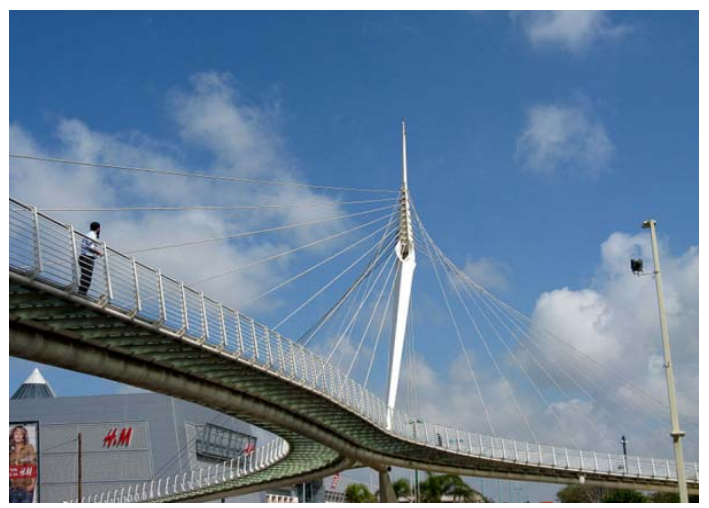

Fig. 1 Footbridge Petah Tikva with transparent steel and glass deck.

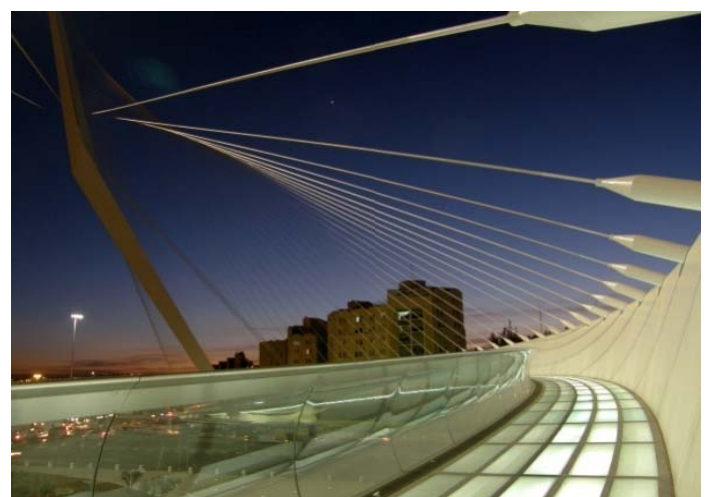

Fig. 2 The chords footbridge with glass deck and glass balustrades. 
length of span is $80.8 \mathrm{~m}$ and the rise of arch is very small (only $4.76 \mathrm{~m}$ ). Steps on deck consist of tempered and laminated glass with four surfaces 10.10.10.4. SGG (Saint Gobain Glass) SATDIP and balustrades panels created three parts of glass SGG STADIP SECURIT PROTECT 15.15.4. Composite structure with steel and glass creates amazing character at place of own localization and it is suitable to historical infrastructure (Fig. 3) [12].

2.2.4 Sundial Footbridge with Glass and Granite Deck

The Sundial Footbridge (Fig. 4) has been the first project of Santiago Calatrava in USA. It is an amazing cable stayed footbridge with spectacular shape of pylon. Transparent deck covered by glass panels looks the most beautiful with night illumination and creates individual form of structure. The Sundial Bridge is a cantilever spar cable-stayed bridge, similar to Calatrava's earlier design of the Puente del Alamillo in Seville, Spain (1992). This type of bridge does not balance the forces by using a symmetrical arrangement of cable forces on each side of its support tower. Instead, it uses a cantilever tower, set at a 42-degree angle and loaded by cable stays on only one side. This design requires that the spar resists bending and torsion forces and that its foundation resists overturning [4].

\section{GFRP Deck in Footbridges}

\subsection{The Possibilities of Composite GFRP Material}

Good exploration of new materials, like composite GFRP, creates possibility to improve this technology and makes comparison analysis with traditional standard of materials. Composite materials are the future of building structures. Durability of structures is always a very important parameter. The past applications of CFRP in bridge structures like improving tapes and lines (wants) of cable stayed bridges have given open gate for composite materials. GFRP-polymer with glass fibre, is a good alternative for traditional material. The properties of GFRP are anisotropy (depending on the type of reinforcement), low density, physical and mechanical properties of composite depending on its components and their respective proportions, high resistance to corrosion and oxidation, relatively high mechanical properties and ability to form complex shapes. Relatively low cost comparing to other kinds of fibres makes E-glass fibres the most commonly used fibres available in the construction industry. The disadvantages of glass fibres are a relatively low Young's modulus, the low humidity and alkaline resistance as well as low long-term strength due to stress rupture.

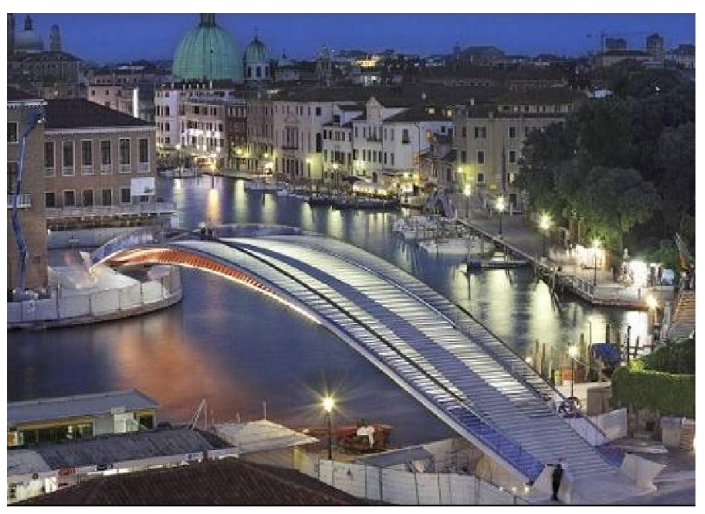

Fig. 3 Transparent effect for Venice Footbridge.
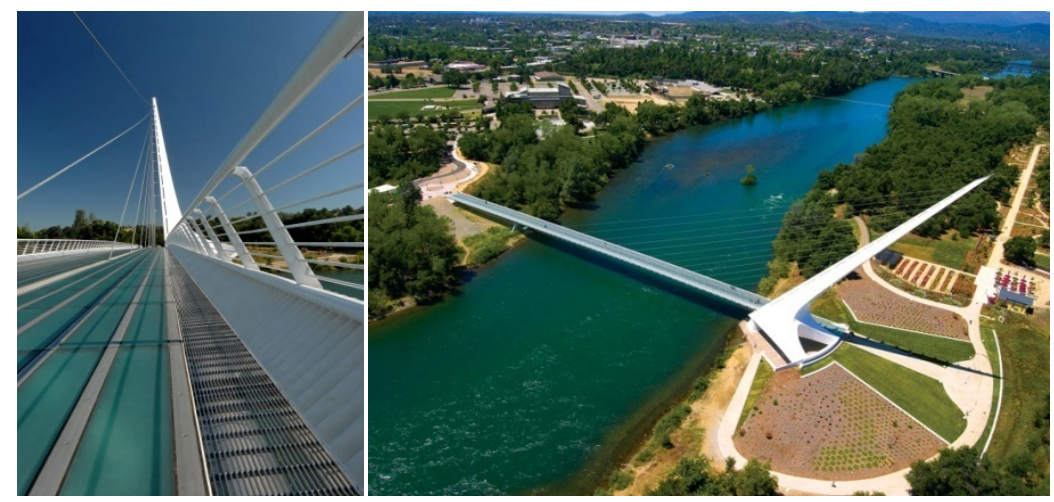

Fig. 4 American Sundial Footbridge. 


\subsection{The Lleida Footbridge with GFRP Fiberline} HD-Type Deck System

The Lleida Footbridge (Fig. 5) is a typical arch structure using extraordinary light fiberline HD (heavy duty plank) system deck created by GFRP orthotropic modules panels. The conception of this bridge gives opportunity of structure creation with modern form, new material technology and longer durability of deck during exploitation. The basic weight of the whole structure's composite GFRP elements is only $19 \mathrm{t}$ [7].

\subsection{Analysis of Chosen Footbridge with Light GFRP} Deck

The existed footbridge in Opole, constructed by laminated wood main beams and wood deck with steel profiles, has been replaced to footbridge with GFRP fiberline HD deck system.

The footbridge in middle size has been located at Bolko Island, in a park of Opole (Fig. 6), after revitalization. There is structure with two independent spans consisting of free ends wooden main beams. That kind of footbridge is very siutable to the outside area of city centrum, among the green natural area of the park.

The key points of numerical FEM (finite element method) analysis have been verified the collaboration between GFRP elements (by fiberline HD deck system) with main beams (by laminated wood GL32C) of footbridge structure. The comparison analysis has been provided for existed wooden deck and hypothetical composite deck. The basic view of footbridge is in
Fig. 7 and the cross section of two conceptions is in Fig. 8. The three 1 st modes and corresponding frequencies are shown in Fig. 9 for footbridge with GFRP deck. The dynamic investigation according to modal analysis for wood deck has been summarized in Fig. 10.

Table 1 consists of natural frequencies for both kinds of decks. Important data base parameters of GFRP deck by fiberline are HD system-modulus of elasticity: 23,000 MPa, weight: $8,530 \mathrm{~g} / \mathrm{m}$, height: $H$ $=40 \mathrm{~mm}$, shear modulus: 3,000 MPa. Light orthotropic

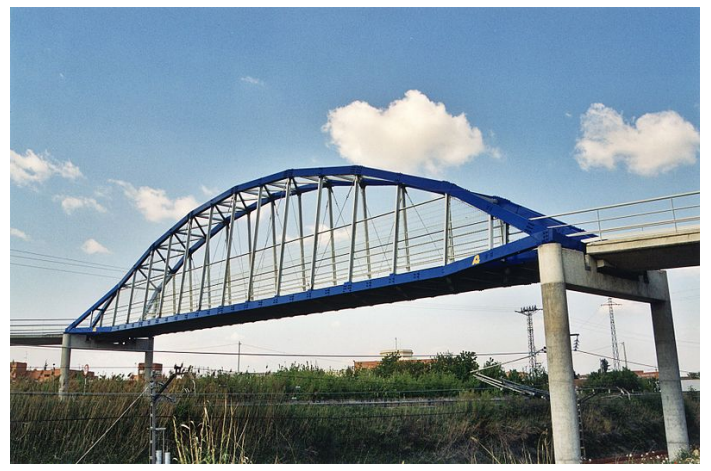

Fig. 5 Arch footbridge with GFRP composite light deck.

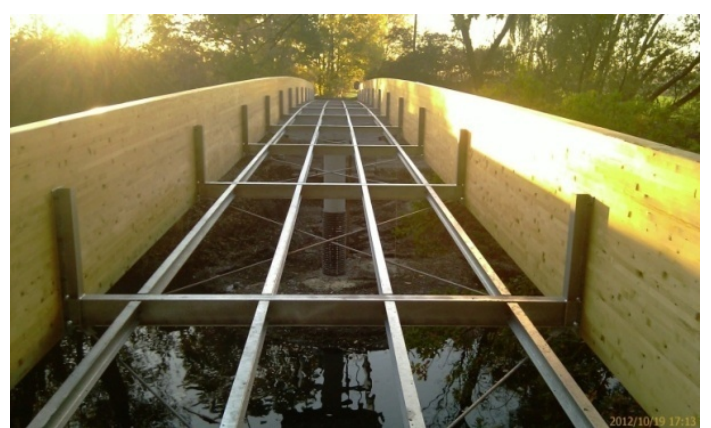

Fig. 6 Footbridge in Opole (during erection) used to FEM analysis.

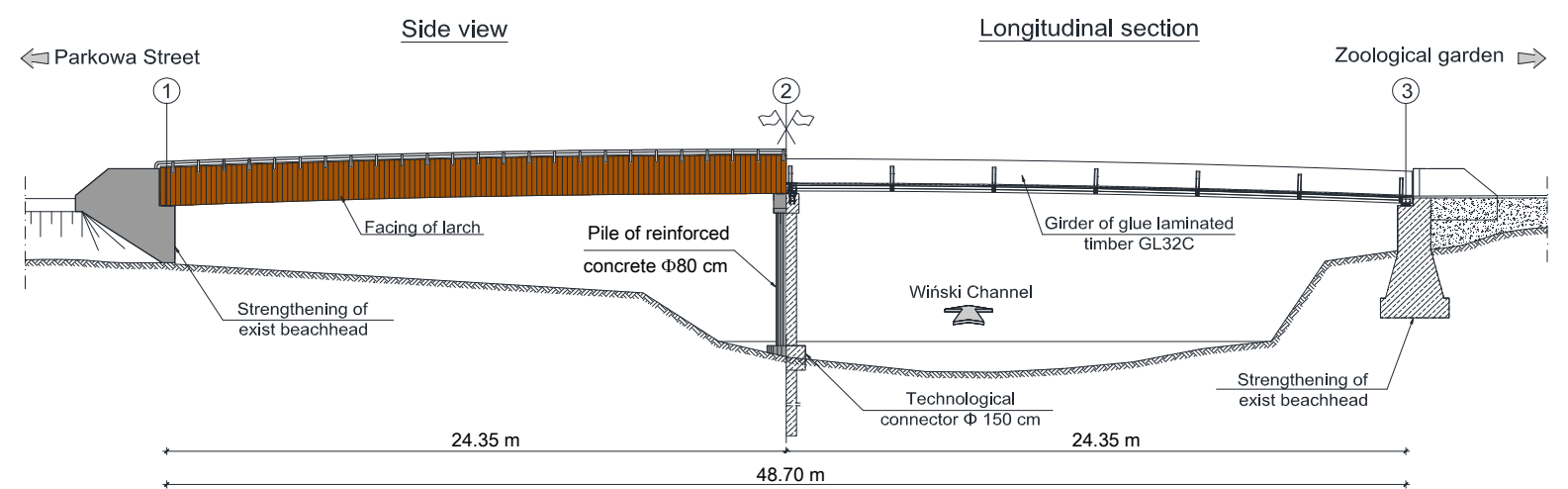

Fig. 7 The main elements of footbridge in Opole at Bolko Island. 


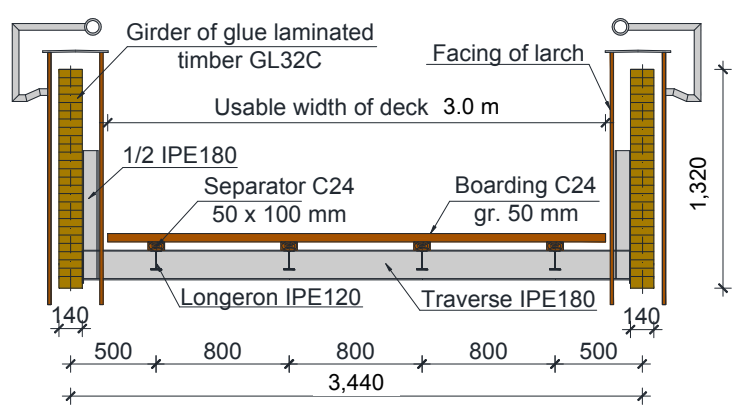

(a)

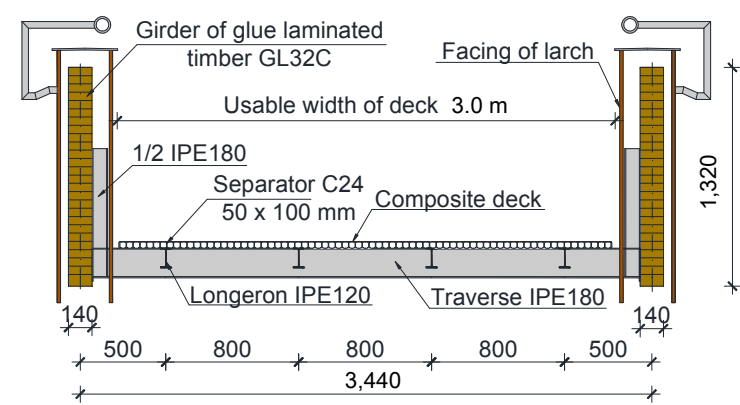

(b)

Fig. 8 Two conceptions of footbridge deck using: (a) wooden panels; (b) GFRP panels (units in mm).

$$
f_{1}=4.88 \mathrm{~Hz}
$$

$f_{2}=4.94 \mathrm{~Hz}$

$$
f_{3}=5.16 \mathrm{~Hz}
$$
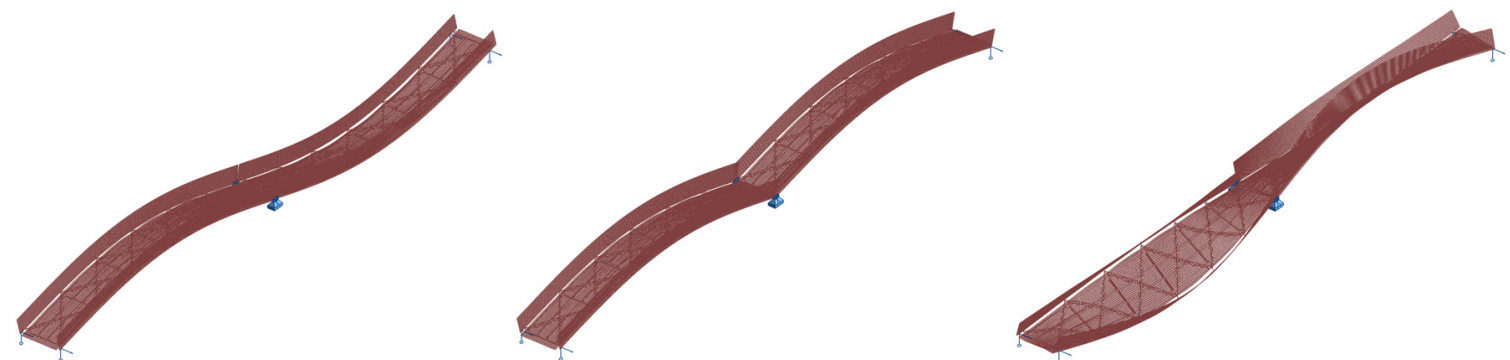

Fig. 9 The 1st three identified modes for footbridge with GFRP deck.

$$
f_{1}=4.42 \mathrm{~Hz}
$$

$$
f_{2}=4.48 \mathrm{~Hz}
$$
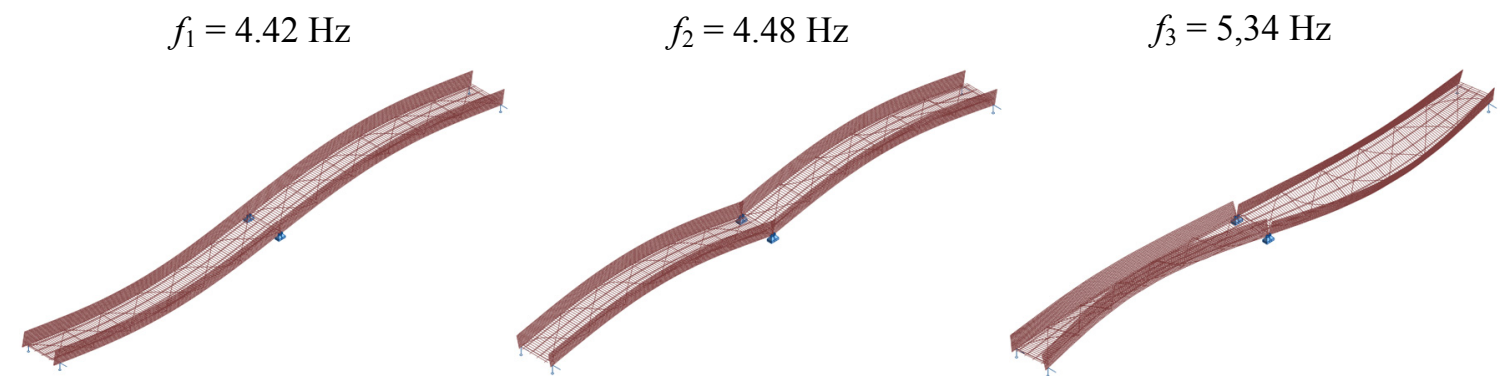

Fig. 10 Identified modes shape for footbridge with wooden deck.

Table 1 The results of modal analysis.

\begin{tabular}{lll}
\hline $\begin{array}{l}\text { The 1st three } \\
\text { modes }\end{array}$ & Wooden deck $(\mathrm{Hz})$ & Composite deck $(\mathrm{Hz})$ \\
\hline 1 & 4.42 & 4.88 \\
2 & 4.48 & 4.94 \\
3 & 5.34 & 5.16 \\
\hline
\end{tabular}

deck is a promising alternative opposite traditional material, opposite typical standard of structure. The FEM analysis has proved it in a simple and basic investigation. Potential high resistance to corrosion of GFRP deck and longer durability create better alternative of such kind of bridge deck.

The dynamic response has been verified according to footfall, using $70 \mathrm{~kg}$ person weight and $2.0 \mathrm{~Hz}$ frequency. That kind of analysis has been applied for both types of footbridge deck [8]. The pedestrian-inducted vibrations and all comparison effects have been presented at Figs. 11 and 12 and in Table $2[7,9]$.

The rules introduced in European standards require verification of natural frequency and level of vibrations of the footbridges. According to EN 1990/A1 verification, the vibration comfort criteria should be performed when the fundamental frequency of the footbridge is less than $5.0 \mathrm{~Hz}$ for vertical vibrations and $2.5 \mathrm{~Hz}$ for horizontal and torsion vibrations. In the cases of medium and large span steel footbridges, the 

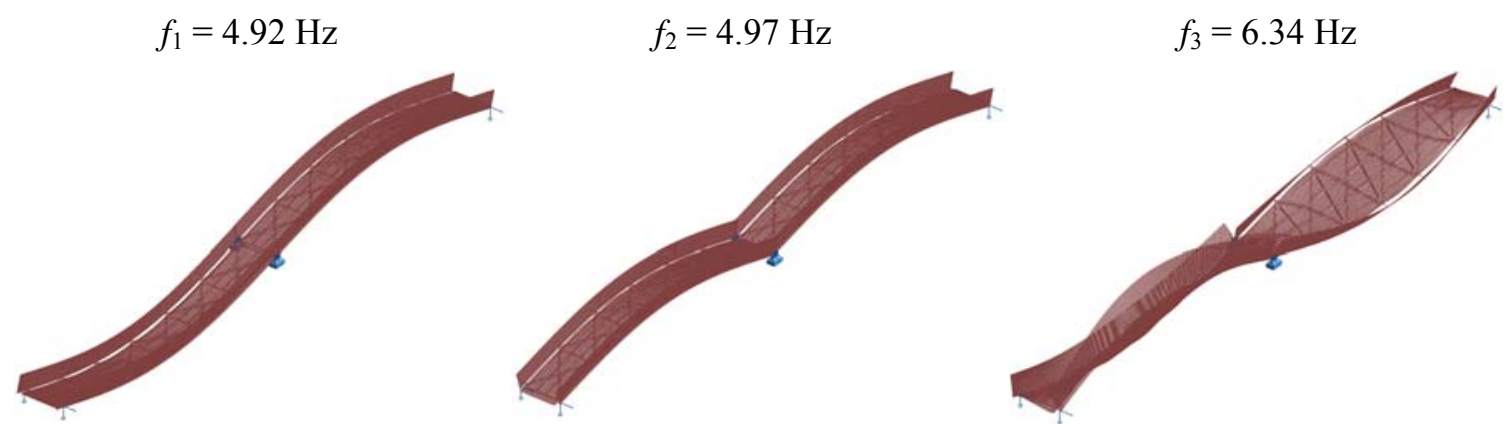

Fig. 11 The pedestrian-inducted vibrations—analyzed footbridge with GFRP deck.
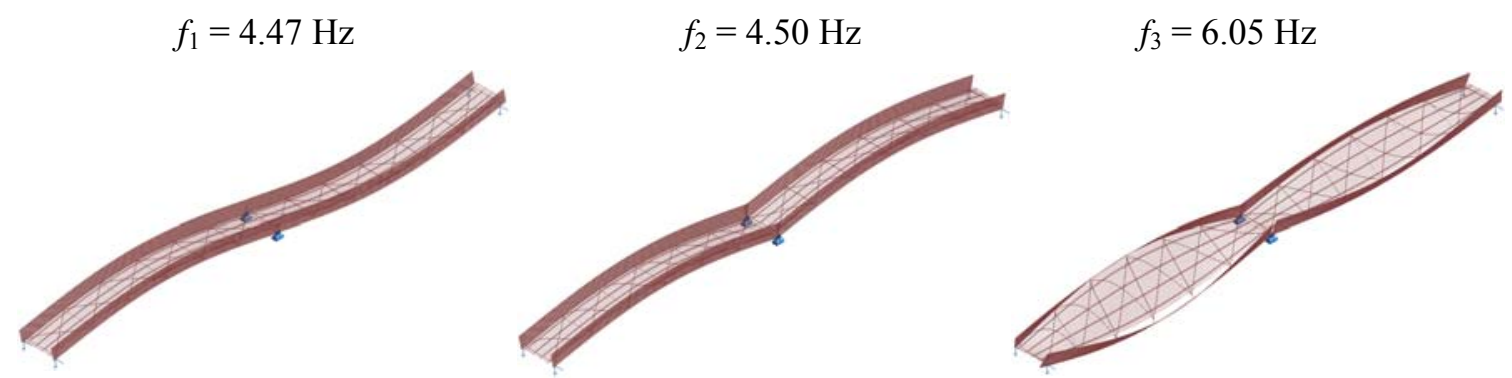

Fig. 12 Footbridge with wooden deck-footfall analysis.

Table 2 Results of footfall analysis.

\begin{tabular}{lll}
\hline Footfall & Wooden deck $(\mathrm{Hz})$ & Composite deck $(\mathrm{Hz})$ \\
\hline 1 & 4.47 & 4.92 \\
2 & 4.50 & 4.97 \\
3 & 6.05 & 6.34 \\
\hline
\end{tabular}

fundamental vertical vibration frequency is very often less than $5.0 \mathrm{~Hz}$. With these reasons, the verification of the vibration comfort criteria becomes obligatory for almost all steel footbridges. Fundamental parameters determining the intensity of vibration perception by human are vibrations amplitude, frequency characteristic of the vibrations, direction of the vibrations, vibrations impact time (exposure time), repeatability of the vibrations and human activity. It should be noted that the recommendations of the EN 1990/A1 exclude the impact of the frequency characteristic of the vibrations and type of human activity on the permissible amplitude of the vibration acceleration. In some cases, the vibrations with amplitudes equal to the values recommended in EN 1990/A1 can be clearly felt by walking and very clearly by standing pedestrians. It is necessary to define the appropriate and accurate criteria. The analyzed footbridge with GFRP composite deck is suitable with EN 1990/A1 normative rules.

\subsection{Interesting Marriage between Architecture and} New Technology in Polish Footbridge

Lightweight structures are nowadays desired in innovative footbridges [2]. Particularly for bridges, the use of GFRP deck pultruded sections could help in creating light span, with a very high degree of lower maintenance cost. Footbridge structure from Gadki, near Kornik over express road S11, is like splendid reference of interesting marriage between architecture and new technology. The project has been created by Prof. H. Zobel's team and it consists of beautiful shape of steel arch connected with GFRP deck in main span. Light modular elements of deck structure are useful for all configurations: curve span, non typical arch, back spans and whole bridge geometry. The described example is an iconic footbridge in Polish topography among new road infrastructure. The footbridge of such dimension is an important and recognizable element of the landscape. All advance dynamic analysis had been created for this project which recommended ideal 


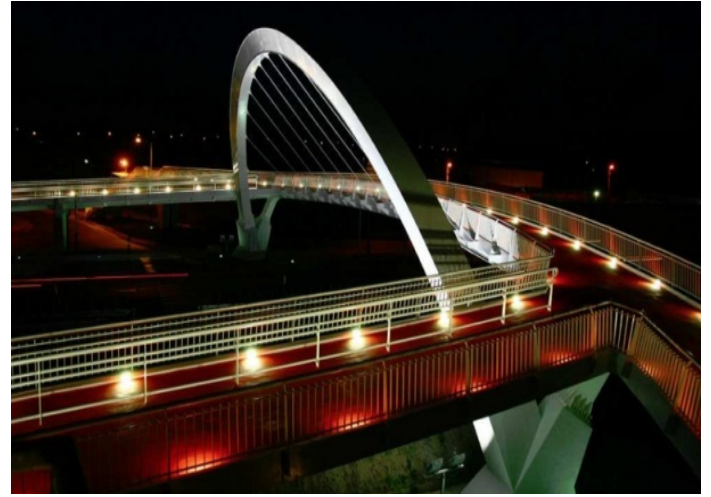

Fig. 13 Arch footbridge with GFRP deck of main span in Gadki (Poland).

solution of GFRP deck application. The challenge of engineering form meets with technical properties of composite material. Arch system has been universal for all time but nowadays, modern technologies create new possibilities in esthetical line and view (Fig. 13) [7].

\section{Conclusions}

Non standard solutions need special verification process. New conceptions of GFRP in footbridge projects must be explored by FEM model analysis. Composite material needs fatigue tests verification, too. Durability of connections between deck's modules and between main beams and deck is very important topic for GFRP applications. Tempered and laminated glass needs individual test trials. Heat soaking process is one method of reducing the incidence of $\mathrm{N}_{i} \mathrm{~S}$ induced failure in tempered glass by causing the phase change to occur before the glass panel is installed in the footbridges. Numerous heat soaking criteria have been developed with different levels of success. In any event, the heat soaking process is not $100 \%$ effective and failures have known to occur with heat soaked tempered glass. The key points of interest are what kind of materials gives longer durability in footbridges projects. New concept of materials determinates future solutions and gives extraordinary development for forms of footbridges. The last three decades has been a period of intensive progressive of tempered, laminated glass and composite retrofit polymer, based on glass fibres [9]. Both of them give new possibilities in modern, attractive architecture and structure creation for footbridges. Modern footbridge architecture needs new inspirations, unusually materials after strength and fatigue tests verification. Monitoring system is useful during footbridge exploitation, because glass panels must be observed and GFRP composite panels ought to be checked according to delamination process of footbridge deck by dynamic load.

\section{References}

[1] Kiel, A. 2011. "Glass for Footbridges. The Subtle Tube in Lisbon." Presented at Workshop of Footbridge 2011, Wroclaw.

[2] Pipinato, A. 2011. "Lightweight Structures and Innovative Materials for Footbridges." Presented at the 4th International Conference, Footbridges 2011, Wroclaw.

[3] Pollak, Z. 2013. "The Research of Quality of Tempered Glass." Presented at the World of Glass, Warsaw.

[4] Stankiewicz, B. 2010. "Santiago Calatrava Bridges with Glass Panels of Deck." Presented at Glass and Ceramics, Warsaw.

[5] Stankiewicz, B. 2013. "The Glass Applications in Bridge Structures." Presented at the World of Glass, Warsaw.

[6] Stankiewicz, B. 2013. "The Glass Deck Panels in Bridge Structures." Presented at the Bridges, Warsaw.

[7] Stankiewicz, B. 2014. GFRP Decks in Bridge Structures. Opole: Opole University of Technology Press.

[8] Stankiewicz, B. 2014. "GFRP Bridge Deck Panel by Material and FEM Analysis." Presented at 1st International Conference Mechanics of Composites, Long Island.

[9] Stankiewicz, B. 2014. "The Possibilities of Glass and GFRP in Footbridges." Presented at 5th International Conference Footbridge 2014, London.

[10] Uffellen, C. 2010. Bridge Architecture + Design. Schweiz: Braun Publishing AG.

[11] Bridge Design and Engineering. 2011. "Footbridge Awards 2011.” Bridge Design and Engineering. Accessed January 5, 2014. http://www.bridgeweb.com. 